\title{
Maltrato de animales: Sentencia del Juzgado de lo penal no 5 de Bilbao (Bizkaia) no 11/2013 de 17 de enero de 2013
} José Manuel Ríos Corbacho ${ }^{1}$

\section{Introducción}

La sentencia objeto de comentario es la del Juzgado de lo penal no 5 de Bilbao (Bizkaia), no 11/2013 de fecha 17 de enero de 2013, cuyo magistrado ponente fue Dña. Arantzazu Ontiñano Sáez; ésta condena por delito de maltrato animal del art. 337 del Código penal a la pena de cuatro meses de prisión con la accesoria de inhabilitación especial para el derecho de sufragio pasivo durante el tiempo de la condena, accesoria de inhabilitación especial para el ejercicio de la profesión, oficio y comercio que tenga relación con animales por tiempo de un año, abono de las costas y una indemnización a Dña. Soraya Gómez Romero, a la sazón, voluntaria de la asociación ASAAM de trescientos cuarenta y ocho euros con treinta y tres céntimos con los intereses preceptuados en el art. 576 de la LEC, por poner fin, de manera cruel, a un perro mestizo de mastín con labrador llamado "Txispa" y cuya titularidad pertenecía a la referida asociación.

\section{Los hechos probados en la sentencia}

En lo referente a los hechos queda probado que D. José Ignacio Lecue Irastorza, en hora no determinada del día 10 de agosto de 2011, con anterioridad en todo caso a las 18.30 horas, encontrándose en la finca de su propiedad sita en el barrio Bidecoche no 14 de Bedia, próxima a la que posee la Asociación Socorro Animal

\footnotetext{
${ }^{1}$ Profesor Titular de Derecho penal de la Universidad de Cádiz

Director del Forum de Derecho, ética y deporte de la Universidad de Cádiz
} 
Amigos Milord (ASAAM) y aprovechando que un perro mestizo de mastín con labrador llamado "Txispa", de titularidad de la referida asociación, se había escapado y colado en dicho predio, quiso poner fin a su vida de forma cruel, pues estaba convencido de que días antes había mordido a alguna de sus ovejas. Ante dicha situación, el hoy condenado cogió una escopeta de su casa disparándola hasta en dos ocasiones, atravesando posteriormente con un objeto puntiagudo la aorta rompiéndole asimismo dos costillas y consiguiendo su objetivo final de darle una muerte dolorosa al can. Junto a ello, cabe decir que la representante de la asociación protectora de animales, Dña. Soraya Gómez Romero, reclama la indemnización que pudiera corresponderte a ésta por el traslado del animal y los gastos de asistencia veterinaria.

Dicha sentencia condena por el delito del maltrato animal fundamentándose en que se observaban los requisitos propios de dicho ilícito no concurriendo ninguna circunstancia modificativa de responsabilidad criminal.

\section{El concepto del ilícito del maltrato de animales}

Se puede definir el delito de maltrato de animales domésticos como aquel que consiste en maltratar injustificadamente por cualquier medio o procedimiento a un animal doméstico o amansado causándole la muerte o lesiones que menoscaben gravemente su salud ${ }^{2}$. A modo de aclaración, habrá que considerar que animal doméstico es aquel que se cría, se reproduce y vive en compañía del ser humano, por placer y con carácter lúdico o social ${ }^{3}$. Por otro lado, los amansados son los que comprenden a los animales fieros o salvajes que sean

\footnotetext{
2 DE VICENTE MARTÍNEZ, R., Vademecum de Derecho penal, Valencia, 2011, pág. 191.
}

${ }^{3}$ REQUEJO CONDE, C., La protección de la fauna. Especial consideración del delito de maltrato de animales, Granada, 2010, págs. 38 y ss. Como domésticos hay que considerar también a los animales de compañía vagabundos o errantes, sin dueño, o que pese a la libertad de movimientos que le es propia, han adquirido la costumbre de regresar a casa teniendo un paradero determinado por el hombre, así como los animales domésticos con potencialidad lesiva como pudieran ser los perros amaestrados. 
amansados por lo que quedan fuera de los mismos los no domésticos y no amansados, excluyéndose el toro de lidia (SAP de Madrid de 9 de julio de 2010) ${ }^{4}$.

Así, puede entenderse que el objeto material del delito de maltrato de animales lo constituye el animal doméstico, en su caso también el amansado, sin necesidad de que tenga que ser propiedad de quien lo maltrata, como apuntan las SSAP de Cáceres de fecha 27 de octubre de 2000 y de Málaga de 8 de marzo de 2001. No obstante, pese a lo anterior el concepto de animal doméstico es un concepto extrapenal que aparece en una ley penal en blanco obligando a acudir al Derecho administrativo fundamentalmente de corte autonómico ${ }^{5}$ que lo define a veces junto con el concepto de animal salvaje y otras veces sin él ${ }^{6}$. Por tanto, bajo la consideración del concepto de animal doméstico, como objeto material del ilícito, puede entenderse que "Txispa" se considera como el objeto del delito juzgado y como tal podría aplicarse el art. $337 \mathrm{CP}^{7}$.

${ }^{4}$ Cfr. AA.VV., "Los delitos relativos a la protección de la flora y fauna y los animales domésticos", en GÓMEZ RIVERO, C., (coord.), Nociones fundamentales de Derecho penal. Parte Especial (adaptado al EEES), Madrid, 2010, pág. 722.

${ }^{5}$ HAVA GARCÍA, E., La tutela penal de los animales, Valencia, 2009, pág. 127. MARQUÉS I BANQUÉ, M., “Comentarios al art. 337”, en QUINTERO OLIVARES, G., (dir.) y MORALES PRATS, F., (coord.), Comentarios a la parte especial de Derecho penal, 5a ed., Pamplona, 2005, pág. 1267.

${ }^{6}$ MUÑOZ LORENTE, J., "Los delitos relativos a la flora, fauna, y animales domésticos: o de cómo no legislar en Derecho penal y cómo no incurrir en despropósitos jurídicos", en Revista de Derecho penal y Criminología (2007), pág. 347. Cfr. RUÍZ RODRÍGUEZ, L.R., "Posición y tratamiento de los animales en el sistema penal", en AA.VV., Los animales como agentes y víctima de daños. Especial referencia a los animales que se encuentran bajo el dominio del hombre, Barcelona, 2008, pág. 190. El autor señala un concepto material centrado en una situación de dependencia material y obligaciones jurídicas entre el animal y el dueño o poseedor, al margen de la inclusión en una u otra categoría por sus características previas. Por otro lado, otros autores han defendido un concepto amplio de animales de compañía, entendiendo que son aquellos que se tiene por afición o por compañía, habitualmente en el hogar, normalmente domesticados y cuidados selectivamente para la convivencia con los seres humanos y sin que el ánimo de lucro constituya el elemento determinante ni principal de su tenencia. En este sentido, PÉREZ MONGUIÓ, J.M., Animales de compañia, Barcelona, 2005, pág. 178.

${ }^{7}$ Una sentencia reciente sobre la posible aplicación del art. 337 CP, véase en REY CERVÓS, M., "Muerte de Sorky Das Point, posibles consecuencias jurídicas en el ámbito penal y en el ámbito deportivo", en http://www.derechoanimal.info/esp/page/2404/muerte-de-sorky-das-pont-posiblesconsecuencias-juridicas-en-el-ambito-penal-y-en-el-ambito-deportivo, pág. 1. Citado el día 6 de febrero de 2013 . 


\section{El iter legislativo}

Si bien es cierto que el delito de maltrato de animales es relativamente reciente (reforma del Código penal de 2003), la protección de los mismos no es novedosa. Así, existen antecedentes cuasi remotos en el CP de 1928, también intitulado como "de Primo de Rivera" donde en su art. 810.4 preveía como falta a "los que públicamente maltrataren a los animales domésticos o los obliguen a una fatiga excesiva", castigándose con una pena de multa de 50 a 500 pesetas $^{8}$. En los siguientes Códigos de 1932 (II República) y 1944, ya no se prevé dicha falta aunque en este último texto si se incluirían algunos preceptos dedicados a los animales como pudieran ser el art. 577.6 que cita el supuesto de arrojar animales muertos y el art. 580.2 del mismo cuerpo legal que aludía al castigo de los dueños de animales feroces o dañinos que se dejasen sueltos o en disposición de causar un mal.

El Código Penal de la Democracia, el de 1995, mantiene en su art. 632, una falta sobre el maltrato cruel a los animales que tenía como referente más cercano la ley 16/70 de 4 de agosto sobre Peligrosidad y Rehabilitación social que configuraba como un estado de peligrosidad en el art. 2.9 a "los que con notorio menosprecio para la comunidad o daño de los animales, las plantas o las cosas" ${ }^{\prime \prime}$.

La propuesta de Código Penal de 1983 incluyó este ilícito en las "faltas contra el orden público", apareciendo en el art. 607 y que establecía una conducta similar con una única diferencia: en lugar de hablar de "con ofensa del sentimiento de los presentes" se dice "ofendiendo los sentimientos de los

${ }^{8}$ HIGUERA GUIMERA, J.F., La protección penal de los animales en España, Madrid, 1994, pág. 61. Cfr. HAVA GARCÍA, E., La tutela penal de los animales, cit., pág. 106. La autora se refiere a esta cuestión en la nota $n^{\circ} 3$.

${ }^{9}$ Otro precedente fue el Proyecto de Código penal de la UCD de 1980 en el que se apuntaba a "Los que maltrataren cruelmente a los animales, con ofensa de los sentimientos de los presentes, serán castigados con la pena de multa de 10 a 60 dias" (art. 685). 
presentes", manteniendo la misma consecuencia jurídica que en el Proyecto anterior.

Tanto en el Proyecto de 1992 como en el art. 620 del Anteproyecto de Código Penal de 1994, dentro de las faltas contra los intereses generales, aparecía la siguiente redacción: "los que maltrataren cruelmente a los animales domésticos o a cualquiera otros en espectáculos públicos no autorizados legalmente, ofendiendo los sentimientos de los presentes y que serían castigados con multa de diez a sesenta días" ${ }^{\prime 10}$.

Como apuntábamos el Código Penal de 1995 establece en su art. 632 establece que "los que maltrataren cruelmente a los animales domésticos o a cualesquiera otros espectáculos no autorizados legalmente, serán castigados con la pena de diez a sesenta días". No obstante, la inestabilidad ideológica de este precepto y lo variopinto ideológicamente hablando del objeto jurídico de protección, junto con las barbaridades que sobre los animales se han producido en los últimos años ha supuesto el impulso de diversas reformas en los textos del Código punitivo, llegando ha incluirse el maltrato cruel como delito.

La reforma operada por la LO 15/2003 dotó de un nuevo contenido al art. $337 \mathrm{CP}$ incluyó un delito en el que se castigaba a quien "maltratare con ensañamiento e injustificadamente a los animales domésticos, causándoles la muerte o provocándoles lesiones que produzcan un grave menoscabo físico, castigándose con pena privativa de libertad de tres a un año, junto con una inhabilitación especial de uno a tres años para el ejercicio de la profesión, oficio o comercio que tenga relación con los animales"11.

${ }^{10}$ RÍOS CORBACHO, J.M., "Los animales como posibles sujetos de Derecho penal. Algunas reflexiones sobre los artículos 631 (suelta de animales feroces o dañinos) y 632 (malos tratos crueles) del Código Penal español", Revista de Derecho Penal de la Universidad de Fribourg, http://perso.unifr.ch/derechopenal/assets/files/articulos/a 20080526 86.pdf, págs. 3 y ss. Citado el día 2 de febrero de 2013.

${ }^{11}$ Cfr. HAVA GARCÍA, E., La tutela penal de los animales, cit., págs. 105 y 106. La autora indica que con este precepto se daba respuesta, aunque poco feliz, a las pretensiones de ciertos grupos de 
Por su parte, el Anteproyecto de Código penal de 14 de noviembre de 2008 dejaba intacta la regulación del momento y el Proyecto de Ley de 27 de noviembre de 2009 hacía lo mismo.

Sin embargo, la reforma operada por la LO 5/2010 de 22 de junio fue una modificación en toda regla de la normativa existente en aquel momento respecto al maltrato animal; así, el primer cambio viene operado por la transformación de la intitulación del capítulo pues de conocerse como "relativo a la flora y la fauna" paso a determinarse como "de los delitos relativos a la protección de la flora, fauna y animales domésticos". Pero esta última reforma también observa una modificación sustancial al modificarse el título donde se ubica dicho capítulo por cuanto ahora pasa a denominarse "De los delitos relativos a la ordenación del territorio y el urbanismo, la protección del patrimonio y del medio ambiente". De esta forma, la primera incongruencia que nos encontramos es que para el legislador, el animal, o más certeramente, el maltrato de los animales domésticos formaría parte del medio ambiente con lo que, a primera vista, el hecho de maltratar un perro afectaría, y mucho, al precitado medio ambiente. Eso muestra la inoportuna, como casi siempre,

opinión que entendían que los animales domésticos debían ser objeto de una protección más rígida, en virtud de los modelos referidos en otros ordenamientos europeos que hace algún tiempo que han renunciado a la mera consideración del animal doméstico como cosa mueble a favor de un planteamiento menos antropocéntrico y mucho más proteccionista respecto del animal y en el que es objeto de preocupación su bienestar, como base del fundamento de su inclusión en el ámbito jurídico-penal. MARQUÉS I BANQUÉ, M., "Comentarios al art. 337", en QUINTERO OLIVARES, G., (dir.) y MORALES PRATS, F., (coord.), Comentarios a la parte especial de Derecho penal, $5^{\mathrm{a}}$ ed., cit., págs. 126y y 1265. SERRA, J.I., "Sentencia definitiva no 86 de la Cámara de Apelaciones en lo civil y en los comercial en lo Contencioso-administrativo de Primera nominación de la segunda circunscripción judicial de Rio Cuarto (Argentina)", http://www.derechoanimal.info/esp/page/2387/los-perros-no-sonsimplemente-una-'cosa'-sentencia-definitiva-nUmero-86-de-la-camara-de-apelaciones-en-lo-civil-ycomercial-y-en-lo-contencioso-administrativo-de-primera-nominacion-de-la-segunda-circunscripcionjudicial-de-rio-cuarto-(Argentina), citado el día 2 de febrero de 2013. Donde se señala que los perros son algo más que una "cosa", aún sin fundamentar en exceso dicha conclusión. 
actuación del legislador para con los problemas actuales de la sociedad ${ }^{12}$; en consecuencia, la realización de una mala política criminal.

Pero han sido más e importantes, en lo que a su contenido se refiere, las modificaciones que dicha reforma otorgo en el precepto 337 del texto punitivo. De tal modo que, entre otras, nos encontramos con la eliminación del requisito de enseñamiento, la incorporación de los animales amansados como objeto del ilícito e incluso la inclusión del término salud, con lo que además de las lesiones físicas también se incorporan las psíquicas muy extendidas en el mundo animal.

Respecto de la primera modificación apuntada por la Reforma de 2010, viene de la mano de la eliminación del enseñamiento que dificultaba notablemente la aplicación del precepto por mor de dotar de una mayor protección a los animales domésticos o amansados frente a los malos tratos que ocasionaren su muerte o menoscabaran gravemente su salud. Por ensañamiento ${ }^{13}$ se venía entendiendo "la complacencia en el sufrimiento del dolor del animal en forma gratuita e innecesaria"14. El hecho de abolir del

12 ZAPICO BARBEITO, M., "Hacia un nuevo bien jurídico del delito de maltrato de animales domésticos y amansados”, Revista Aranzadi de Derecho y Proceso penal, no 25 (2011), pág. 15.

${ }^{13}$ Sentencias basadas en el enseñamiento pueden verse en REQUEJO CONDE, C., La protección de la fauna. Especial consideración del delito de maltrato de animales, cit., págs. 45 y ss. Cfr. HAVA GARCÍA, E., La tutela penal de los animales, cit., págs. 112 y ss. RUÍZ RODRÍGUEZ, L.R., "Posición y tratamiento de los animales en el sistema penal", en AA.VV., Los animales como agentes y víctima de daños. Especial referencia a los animales que se encuentran bajo el dominio del hombre, cit., pág. 190. ZAPICO BARBEITO, M., "Hacia un nuevo bien jurídico del delito de maltrato de animales domésticos y amansados", Revista Aranzadi de Derecho y Proceso penal, no 25 (2011), pág. 22. Esta autora al hablar de enseñamiento señala que el abandono del animal que le cause la muerte o lesiones que menoscaben gravemente su salud será considerado ya como delito del art. $337 \mathrm{CP}$ pues cuando en el tenor literal del precepto aún se exigía el ensañamiento, se impedía que dicha circunstancia se pudiera subsumir en el tipo. También esta autora, cita la Sentencia del Juzgado de lo penal $n^{\circ} 1$ de Vinaroz, $n^{\circ} 33 / 2005$ en la que se condena a cinco meses de prisión al acusado de haber matado a un perro ahorcándolo con una soga y colgándolo de un árbol, considerando que con ello se provocaron padecimientos innecesarios a un animal, lo que debe ser entendido como ensañamiento, sin reparar que podría faltar el elemento subjetivo exigido por el ensañamiento

14 RAMÓN RIBAS, E., "El maltrato de animales y la custodia de animales", en QUINTERO OLIVARES, G., (Dir.), La reforma Penal de 2010: Análisis y Comentarios, Pamplona, 2010, pág. 298. Cita el autor la SAP de Baleares, sección $1^{\text {a }}$, 226/1997, de 24 de diciembre. También señala el hecho del "deleite en hacer el mal o complacencia en los padecimientos causados voluntariamente, sin justificación 
precepto dicho concepto venía determinado por la necesidad de producir un sufrimiento adicional al causado por la propia lesión o lesiones infligidas o por la forma de ejecutar la muerte que se hubiera elegido, desde el plano objetivo, mientras que se necesitaría un particular ánimo del sujeto desde el plano subjetivo $^{15}$. Sin embargo, quizá haya que apuntar también a la mala utilización del legislador del concepto enseñamiento. Sin lugar a dudas, este concepto es un sustantivo muy definido en el Código Penal ya que se trata de una de las agravantes generales ubicadas en el art. 22. De forma que en su número 5 se habla de que nos encontramos ante una agravante en la que se "aumenta deliberada e inhumanamente el sufrimiento de la víctima, causando a ésta padecimientos innecesarios para la ejecución del delito"16. Si utilizamos la interpretación auténtica determinada por el Derecho penal ${ }^{17}$ el propio texto del Código nos habla de "inhumanamente", pero es una circunstancia muy curiosa pues al tratarse aún los animales como cosas muebles el concepto inhumanidad como umbral del dolor humano no habría posibilidad de aplicar, con cierto raciocinio, tal precepto a dichos seres vivos puesto que al no ser humanos no podemos percibir que amplitud de dolor pueden aguantar al objeto de que se pueda aplicar el ilícito del art. 337 CP.

La segunda modificación de la reforma 2010 se determino por el aumento de las lesiones penalmente relevantes puesto que no sólo incluiría las de carácter físico sino también las de carácter psíquico ${ }^{18}$ que con anterioridad

alguna que no fuera el propio placer de hacer sufrir sin otro motivo". Para argumentar esta cuestión, cita la SAP de Valencia, Sección $3^{\mathrm{a}}$, 656/2000, de 9 de diciembre.

${ }^{15}$ Loc.cit.

16 DE VICENTE MARTÍNEZ, R., Vademecum de Derecho penal, cit., pág. 125. LA MISMA, "Circunstancias de la responsabilidad criminal", en DEMETRIO CRESPO, E., (Coord.), Lecciones y materiales para el estudio del Derecho penal, Teoría del delito, Tomo II, Madrid, 2011, pág. 391 y 392.

${ }^{17}$ MUÑOZ CONDE, F., y GARCÍA ARÁN, M., Derecho penal. Parte general, $8^{\mathrm{a}}$ ed., Valencia, 2010, pág. 125.

${ }^{18}$ Esta incorporación de la preocupación por la salud psicológica de los animales abre un camino para la protección de los animales domésticos o amansados en las granjas de explotación que, debido a las 
sólo se podría sancionar a través de la falta de maltrato cruel del art. 632.2 $\mathrm{CP}^{19}$. La tercera modificación se refiere al objeto material del delito ya que además de los animales domésticos también va a incluir a los "amansados" 20.

Pero no podemos finalizar este apartado sin traer a colación la posible futura reforma del Ministro Gallardón en el Anteproyecto de Ley de 2012, en lo que al maltrato animal se refiere. De esta forma, frente a la legislación actual, el Anteproyecto incorpora como delito el abandono a aquel que se produce sobre el animal doméstico en condiciones en las que pueda peligrar su vida o integridad, siendo castigado con la pena de multa de uno a seis meses. Quizá el legislador ha optado por darse cuenta que desde la política criminal se observa que más de 200.000 animales son abandonados cada año, en virtud de ser camadas de cachorros indeseadas, cambios de domicilio familiares, factores económicos y pérdida de interés por el animal ${ }^{21}$. Estos datos son lo

condiciones de hacinamiento en las que viven, sin poder echarse en la tierra a descansar, atacándose a sí mismos e hiriendo a otros animales, no sólo experimentan padecimientos físicos, sino también trastornos psicológicos. Cfr. ZAPICO BARBEITO, M., "Hacia un nuevo bien jurídico del delito de maltrato de animales domésticos y amansados", cit., pág. 25.

19 RAMÓN RIBAS, E., "El maltrato de animales y la custodia de animales", en QUINTERO OLIVARES, G., (Dir.), La reforma Penal de 2010: Análisis y Comentarios, cit., pág. 298. Hay que indicar que no podemos obviar el maltrato psíquico en los animales por cuanto muchos de los animales abandonados o que son objeto de crueles palizas suelen conllevar un comportamiento psíquico irregular, normalizado en perreras donde es imposible realizar una atención personalizada y que, todo lo más, pueden ser relativizados por el comportamiento de los adoptantes de dichos animales, adopción que poco a poco suele hacerse más frecuente.

${ }^{20}$ Ibid., pág. 298 y 299. Este autor señala que al poner en plano de igualdad a los animales domésticos "o" amansados, también habría que incluir dentro del concepto de animal doméstico a los efectos penales a los de "rentas" y a los criados para el aprovechamiento de sus producciones, esto es, animales que no son de compañía, pero que tampoco son salvajes, puesto que no se entenderían que se incluyeran unos y no los otros. En este sentido, la opinión del Consejo General del Poder Judicial que en el Informe sobre el Anteproyecto de Ley Orgánica de reforma de la Ley Orgánica 10/1995 afirma que "el reproche social por la especial sensibilidad que hoy en día se tiene hacia los animales en cuanto que seres sintientes justifica una igualdad de trato entre los animales domésticos en sentido estricto, los domesticados o incluso los mantenidos en cautividad". AA.VV., "Los delitos relativos a la protección de la flora y fauna y los animales domésticos", en GÓMEZ RIVERO, C., (coord.), Nociones fundamentales de Derecho penal. Parte Especial (adaptado al EEES), cit., pág. 722.

21 http://www.antena3.com/especiales/noticias/ciencia/hazte-eco/noticias/200000-animales-sonabandonados-espana-cada-ano_2012062500148.html. Citado el día 3 de febrero de 2013. Se advierte que 
suficientemente contundentes para que el Código Penal incorpore el tema del abandono ya como delito.

\section{El problema del bien jurídico en el maltrato animal}

Sin lugar a dudas, si hay un cuestión discutida en el ámbito del Derecho penal de los animales es la del verdadero bien jurídico en este ilícito, circunstancia ésta que aún no ha encontrado anuencia entre la doctrina.

Varios han sido los posicionamientos sobre este tema pero parece que es determinante para su consideración la conceptuación del animal doméstico como objeto sobre el que recae la acción o si son sujetos pasivos del delito; éstos han llegado a considerarse como meras cosas muebles o semovientes que pudieran suponerse como objeto de posesión o de propiedad; no obstante, el hecho de que además de haberse considerado objeto material se reflejaran como sujetos pasivos del ilícito, supondría, como no puede ser de otra manera, derechos subjetivos y que, a su vez, pudieran ser determinados como bienes jurídicos ${ }^{22}$.

La primera de las tesis con la que se quiere definir el bien jurídico es aquella que los ubica en el medio ambiente, entendiendo que el mandato

cada tres minutos y medio se abandona un animal de compañía (uno de cada tres es un cachorro). Otro dato es que de los animales de compañía serán el 31\% de perros y el 5\% serían gatos.

${ }^{22}$ ZAPICO BARBEITO, M., "Hacia un nuevo bien jurídico del delito de maltrato de animales domésticos y amansados", cit., pág. 22. CABRERA CARO, L., "Autonomía y dignidad; la titularidad de los derechos", en Anuario de los derechos humanos, vol, 3 (2002), pág. 19. Señala la autora que seguimos anclados en la herencia ilustrada. Hasta cierto punto, prosigue, es lógico que así sea, pues la personalidad, en definitiva, es la causa por excelencia del Derecho. Es por dicha circunstancia por la que sólo las personas pueden ser sujetos de derechos, y que los animales, las plantas o las rocas, sólo puedan ser objetos del mismo. Cfr. MEJÍAS, J.J., "Derechos humanos y Medio ambiente", en Humana Iura, 10 (2000), pág. 39. Para este autor sólo el hombre es capaz de llevar a cabo una actuación moral consciente y libre y, por tanto, sólo él puede ser considerado sujeto de derechos. Sobre la necesidad de alejar la pretérita separación entre sujeto y objeto, véase, HELIZALDE HEVIA, A., "Derechos de la naturaleza. ¿Problema jurídico o problema de supervivencia colectiva?”, en ACOSTA, A., y MARTÍNEZ, E., (comp.), Derechos de la naturaleza. El futuro es ahora, Quito, 2009, págs. 70 y ss. 
constitucional recogido en el art. 45 sobre éste incluiría igualmente la tutela de animales domésticos ${ }^{23}$. Asímismo, los partidarios de esta posición entienden el medio ambiente en un doble sentido: de un lado, como peligro al medio ambiente, ya que el desarrollo de la técnica ha posibilitado cada vez más una mayor explotación de la naturaleza, en sus distintos componentes, considerándose uno de ellos el desarrollo animal como presupuesto para la existencia humana que sería la que verdaderamente sería puesta en peligro; un segundo, sería el daño a la incolumnidad de los animales en su aspecto físico y psíquico, como consecuencia de poner en riesgo el medio ambiente ${ }^{24}$; sin embargo, esta tesis no ha sido muy seguida en virtud de que no parece que la tutela penal del medio ambiente tenga mucho que ver con la protección que ahora se le concede a los animales domésticos, aunque se le haya ubicado junto a los ilícitos medioambientales, ya que parece que con la primera tutela se protege el equilibrio de los sistemas naturales, mientras que con la segunda de lo que se trata es de salvaguardar el sufrimiento de los animales domésticos frente a las conductas humanas ${ }^{25}$.

${ }^{23}$ ROCA FERNÁNDEZ-CASTANYS, M.L., "Los animales domésticos y el Derecho: en particular, el régimen jurídico de los animales de compañía", en AA.VV., Panorama jurídico de las Administraciones Públicas en el siglo XXI. Homenaje al Profesor Eduardo Roca Roca, Madrid, 2002, págs. 1209 y ss. SERRANO TÁRREGA, M., "El maltrato de animales en el Código Penal", La Ley, 3 (2005), págs. 1841 y ss. LA MISMA., "El maltrato de animales", Revista de Derecho penal y Criminología, núm. Extraordinario 2 (2004), pág. 521. Son de esta opinión en la doctrina alemana, WIEGAND para quien la norma lejos de ubicarse en una ley especial, como sucede en su país, señala que debería estar tipificada en el Código Penal, afirmando que se pone en peligro el medio ambiente cuando se daña la integridad física o psíquica del animal al matarlo o al maltratarlo cruelmente. Cfr. MORIE, R., Das Vergehen der Tierquälerei. Eine strafrechtliche Untersuchung zu $\$ 17$ T über bes. Berücksichtigung staatsanwalts-schaftlicher und gerichtlicher Strafakten aus Niedersachsen in den Jahren 1974-1981, 1984, pág. 186. GREVEN, G., Die Tierhaltung aus strafrechtlicher Sicht, 1998, pág. 237. RÖCKLE, A.G., Probleme und Entwicklungstendenzen des strafrechtlichen Tierschutzes, 1996, pág. 88. Vid por todos, REQUEJO CONDE, C., La protección de la fauna. Especial consideración del delito de maltrato de animales, cit., pág. 30. A esta circunstancia se refiere en la nota 53 de su trabajo.

${ }^{24}$ Cfr. REQUEJO CONDE, C., La protección de la fauna. Especial consideración del delito de maltrato de animales, cit., pág. 31.

${ }^{25}$ En este sentido, HAVA GARCÍA, E., La tutela penal de los animales, cit., págs. 114 y 115 . La autora fundamenta su rechazo a este bien jurídico observando, de manera gráfica que los sufrimientos infligidos a un cordero poco antes de su sacrificio o a un toro bravo en su lidia antes de su muerte o 
Otra de las teorías viene determinada por la consideración de los "intereses generales" como objeto jurídico de protección en el delito de maltrato animal; éstos se han focalizado de diversas formas, ya que puede entenderse como medio, portador y productor de valores culturales ${ }^{26}$ y otras veces lo que se intenta salvaguardar es el hecho de que se protejan los sentimientos de no ver sufrir al animal ${ }^{27}$ e incluso se ha llegado a incluir el hecho del mantenimiento de la paz entre los ciudadanos ${ }^{28}$.

Basándose en las ideas de Aristóteles también existía la teoría que concebía que el bien jurídico era la moral y las buenas costumbres, en el sentido de que un maltrato hacia los animales en el pasado podría llegar a ser

incluso un ratón durante un experimento científico no perjudican en absoluto la conservación y mejora de las circunstancias que hacen posible la supervivencia y la calidad de la vida de los hombres; es más, continúa, indicando que hay veces en las que hay que exterminar a ciertos animales a fin de restablecer el equilibrio de la naturaleza. Además, el hecho de incluir también el maltrato de animales domésticos dentro de los delitos contra la flora y la fauna ha sido considerado un dislate jurídico. LA MISMA, "Delitos relativos a la protección de la flora, fauna y animales domésticos", en ÁLVAREZ GARCÍA, F.J., (Dir.), MANJÓN-CABEZA OLMEDA, A., y VENTURA., (Coords.), Derecho penal español. Parte Especial (II), Valencia, 2011, págs. 1109 y 1110. En el mismo sentido, MUÑOZ LORENTE, J., "Los delitos relativos a la flora, fauna, y animales domésticos: o de cómo no legislar en Derecho penal y cómo no incurrir en despropósitos jurídicos”, en Revista de Derecho penal y Criminología (2007), págs. 309 y ss. Entiende este autor que lo único que tiene de común el maltrato de animales domésticos con el resto de los ilícitos circundantes es el objeto material. REQUEJO CONDE, C., La protección de la fauna. Especial consideración del delito de maltrato de animales, cit., pág. 31. DOMENECH PASCUAL, G., "La posibilidad de limitar los derechos fundamentales en aras del bienestar animal", Revista Interdisciplinar de Gestión Ambiental, 74 (2005), pág. 13. Cfr. MARTÍNEZ-BUJÁN PÉREZ, C., Derecho penal económico y de la empresa. Parte especial, $2^{\mathrm{a}}$ ed., Valencia, 2005, pág. 834. VERCHER NOGUERA, A., "La reforma introducida por la Ley orgánica 15/2003, de 25 de noviembre en materia penal ambiental o la exigencia de un reajuste inevitable", en Actualidad Jurídica Aranzadi, 665 (2005), pág. 12. ZAPICO BARBEITO, M., "Hacia un nuevo bien jurídico del delito de maltrato de animales domésticos y amansados”, cit., pág. 16.

${ }^{26}$ SERRANO TÁRREGA, M., “El maltrato de animales en el Código Penal”, cit., págs. 1841 y ss.

${ }^{27}$ ROCA AGAPITO, L., “Algunas reflexiones sobre los animales y el Derecho penal. En particular el art. 631 del Código Penal, Actualidad Penal, 1996, pág. 401. En contra, RUÍZ RODRÍGUEZ, L.R., "Posición y tratamiento de los animales en el sistema penal", en AA.VV., Los animales como agentes y víctima de daños. Especial referencia a los animales que se encuentran bajo el dominio del hombre, cit., pág. 187.

${ }^{28}$ Vid por todos, REQUEJO CONDE, C., La protección de la fauna. Especial consideración del delito de maltrato de animales, cit., pág. 32. 
un maltrato sobre las personas en el futuro ${ }^{29}$. En este sentido, no se va a proteger a los animales en función de lo que son, sino en función de los intereses sociales, por lo que puede señalarse que el bien jurídico sería difuso, el del conjunto de la sociedad en su conjunto y donde el animal tan sólo sería el objeto material del ilícito ${ }^{30}$.

Una nueva tesis doctrinal viene determinada por la relación especial que se produce entre lo humano y lo animal; de modo que se ha introducido el referente humano situando como objeto material de la acción del maltrato sólo a los animales domésticos, que son a los que apunta en el tenor literal del precepto el legislador, a fin de excluir la prohibición de ciertas actividades especiales o bien para facilitar claramente la identificación de su objeto ${ }^{31}$.

La tesis más acogida por la doctrina es aquella en la que sin renunciar a una estructura antropocéntrica, apunta a los sentimientos de las personas como objeto de la tutela de los tipos penales y ello porque muchas personas sufren en su salud al saber que se maltrata a esas criaturas $^{32}$. En este punto sostiene Hava García que aún reconociendo que han sido los sentimientos humanos de amor y compasión para con los animales los que han llevado a otorgar cierto estatus al animal, a partir de ahí la interpretación de los tipos protectores de los animales deben seguir su propio camino, y que por tanto de igual modo que en los delitos contra el patrimonio histórico en si mismo y no

${ }^{29}$ Cfr. HAVA GARCÍA, E., La tutela penal de los animales, cit., pág. 118 a 121.

30 Cfr. ZAPICO BARBEITO, M., "Hacia un nuevo bien jurídico del delito de maltrato de animales domésticos y amansados”, cit., pág. 18.

${ }^{31}$ RUÍZ RODRÍGUEZ, L.R., "Posición y tratamiento de los animales en el sistema penal", en AA.VV., Los animales como agentes y víctima de daños. Especial referencia a los animales que se encuentran bajo el dominio del hombre, cit., pág. 186. Este autor señala que se debe declinar como bien jurídico el valor patrimonial del animal en cuanto que al ser un delito común lo puede cometer cualquiera.

32 GUZMÁN DALBORA, J.L., "El delito de maltrato de animales", en AA.VV., La ciencia del Derecho penal ante el nuevo siglo. Libro homenaje al Prof. Dr. D. José Cerezo Mir, Madrid, 2002, pág. 14. KRIELE, M., "Gesetzliche Regelungen von Tierversuchen und Wissenschaftsfreiheit", en HÄNDEL, U.M., (coord.), Tierschutz. Testfall unserer Menschlichkeit, Frankfurt a. Händel, M., 1984, pág. 120. 
los sentimientos que despierta en las personas la contemplación del arte, la "sociedad" valora a los animales como bienes jurídicos dignos de protección frente a las agresiones más graves que le produzcan sufrimientos y deben ser estos mismos los que se consideren protegidos por la norma. De esta manera, dice esta autora que nos encontramos con un bien jurídico colectivo (cuyo titular sería la propia sociedad) y ello obliga a interpretar que el tipo penal examinado sería un delito de infracción de un deber ya que de la normativa que reconoce los derechos de los animales fluyen unos deberes bioéticos del hombre para con los animales que entendería al bien jurídico como la obligación de no someter a los animales domésticos a malos tratos o de tratarlos con benevolencia ${ }^{33}$.

Frente a todas estas posiciones sobre el objeto jurídico de protección, y sin quitarles mucha razón, debo entender un bien jurídico diferente, como ya expusiera hace más de una década, cuando aún no existía el delito de maltrato de animales y tan sólo existía en el antiguo art. 632 la falta sobre el maltrato cruel. Así, entendía que el bien jurídico protegido sería la vida, la integridad física y psíquica del animal ${ }^{34}$ e incluso su dignidad ${ }^{35}$.

${ }^{33}$ En este sentido, HAVA GARCÍA, E., La tutela penal de los animales, cit., pág. 122. LA MISMA, "Delitos relativos a la protección de la flora, fauna y animales domésticos", en ÁLVAREZ GARCÍA, F.J., (Dir.), MANJÓN-CABEZA OLMEDA, A., y VENTURA., (Coords.), Derecho penal español. Parte Especial (II), cit., pág. 1111.

${ }^{34}$ RÍOS CORBACHO, J.M., "Los animales como posibles sujetos de Derecho penal. Algunas reflexiones sobre los artículos 631 (suelta de animales feroces o dañinos) y 632 (malos tratos crueles) del Código Penal español", Revista de Derecho Penal de la Universidad de Fribourg, http://perso.unifr.ch/derechopenal/assets/files/articulos/a 20080526 86.pdf, págs. 13 y ss. Citado el día 6 de febrero de 2013. Cfr. HAVA GARCÍA, E., La tutela penal de los animales, cit., pág. 116. LA MISMA, "Delitos relativos a la protección de la flora, fauna y animales domésticos", en ÁLVAREZ GARCÍA, F.J., (Dir.), MANJÓN-CABEZA OLMEDA, A., y VENTURA PÜSCHEL, A., (Coords.), Derecho penal español. Parte Especial (II), cit., pág. 1110. RUÍZ RODRÍGUEZ, L.R., "Posición y tratamiento de los animales en el sistema penal", en AA.VV., Los animales como agentes y víctima de daños. Especial referencia a los animales que se encuentran bajo el dominio del hombre, cit., pág. 186. A esta circunstancia se refiere en la nota $\mathrm{n}^{\circ}$ 50. REQUEJO CONDE, C., La protección de la fauna. Especial consideración del delito de maltrato de animales, cit., págs. 34 y 35. ZAPICO BARBEITO, M., "Hacia un nuevo bien jurídico del delito de maltrato de animales domésticos y amansados”, cit., pág. 22. 
Pues bien, a la hora de argumentar mi posición, se parte de que el propio legislador está considerando una preocupación cada vez mayor por los animales, de tal manera que el supuesto protegido va a superar la propia sensación de piedad que genera en los seres humanos.

Lo primero que hay que indicar es que la idea no es poner en plano de igualdad los derechos subjetivos de animales y de los hombres, cuestión esta que no tendría coherencia ninguna ${ }^{36}$, pero si defender un bien jurídico propio del animal ${ }^{37}$.

La idea de la independencia de la protección animal (en lo que a los animales domésticos se refiere que son los que aparecen en el tenor literal del precepto) debe basarse en las propuestas de Benthan donde al referirse a los animales comienza a sobreentender la capacidad de sufrimiento de los mismos, de tal manera que indica el hecho de que la cuestión no es si estas criaturas pueden razonar o si pueden hablar sino que la verdadera cuita es si pueden sufrir $^{38}$.

Así, el sufrimiento del animal es lo verdaderamente relevante para concebir el bien jurídico protegido.

${ }^{35}$ Como expone la SAP de Madrid de 19 de abril de 2004. Todo ello incluye el bienestar animal o el animal en sí mismo considerado.

${ }^{36}$ HAVA GARCÍA, E., La tutela penal de los animales, cit., pág. 116.

${ }^{37}$ En este sentido, se ha propuesto una posible tipificación en un Título XVI bis del delito de maltrato animal para que no se desvirtúe el bien jurídico protegido del Titulo XVI sobre el medio ambiente, como acertadamente propone MUÑOZ LORENTE, J., MUÑOZ LORENTE, J., "Los delitos relativos a la flora, fauna, y animales domésticos: o de cómo no legislar en Derecho penal y cómo no incurrir en despropósitos jurídicos", cit., pág. 314. Cfr. REQUEJO CONDE, C., La protección de la fauna. Especial consideración del delito de maltrato de animales, cit., pág. 35.

${ }^{38}$ BENTHAN, J., Introduccion to the Principles of morals and Legislation, London, 1970, págs. 282 y 283. Utiliza el autor cierto parangón para exponer su tesis a la relación de unos hombres con otros como pudiera ser la esclavitud, por el color de la piel, con el trato que los propios hombres realizan con respecto a las razas inferiores. Pero dicho autor sostiene la idea de los animales indicando que "un caballo o un perro adulto es, más allá de toda comparación, un animal más racional y con los cuales es más posible comunicarse, que un niño de un día, de una semana e incluso de un mes. Cfr. BLASCO, A., Ética y bienestar animal, Madrid, 2011, pág. 135. SINGER, P., Liberación animal, Madrid, 2011, págs. 23 y 24. 
No obstante, se han prescrito diversas objeciones, de modo que se ha llegado a decir (cuando existía aún en el ilícito el enseñamiento) ${ }^{39}$ que si se concretara el bien jurídico vida o salud del animal la muerte o lesión sin ensañamiento se debería castigar. Este argumento cae por su propio peso por cuanto ya no existe la circunstancia del ensañamiento en el tenor literal del art. $337 \mathrm{CP}$.

Igualmente, pudieran llevar razón, desde el punto de vista de que entender al bien jurídico general como "satisfacción de necesidades humanas" ${ }^{40}$, aquellos que sostienen que los animales no tienen derecho a la vida o integridad física o psíquica puesto que el reconocimiento de los mismos significaría la frustración de determinadas necesidades humanas, reconocidas fundamentalmente en el texto constitucional español, aceptando que el derecho lo tiene la sociedad ya que esta valora a los animales como bienes dignos de protección ${ }^{41}$. Quizá el punto de inicio del planteamiento puede ser ese, pero hoy día el legislador, después de la reforma 5/2010, parece dejar intacto el delito del maltrato en el Anteproyecto de 2012, manteniendo un ilícito en el que crea un tipo muy parecido al delito de lesiones en los humanos, con la diferencia en que el objeto material es el animal "doméstico" o "amansado", lógicamente, en este tránsito legislativo hacia el reconocimiento de los derechos de los animales propio de esta época. De esta forma, los parámetros en los que se muestra el delito viene de la mano de que "por cualquier medio o procedimiento" se maltrate injustificadamente y causándole muerte o lesiones que menoscaben gravemente la salud; aquí el legislador ha

${ }^{39}$ RUÍZ RODRÍGUEZ, L.R., "Posición y tratamiento de los animales en el sistema penal", en AA.VV., Los animales como agentes y víctima de daños. Especial referencia a los animales que se encuentran bajo el dominio del hombre, cit., pág. 187.

40 TERRADILLOS BASOCO, J., "La satisfacción de necesidades como criterio de determinación del objeto de tutela jurídico-penal", en Revista de la Facultad de Derecho de la Universidad Complutense , 63 (1981), págs. 136 y ss.

${ }^{41}$ HAVA GARCÍA, E., La tutela penal de los animales, cit., pág. 116. 
explicitado un tipo similar al de lesiones humanas por cuando afecta a la salud, por lo que puede apuntarse a la vida o a la integridad física y psíquica del animal que van imbuidas en el concepto salud (en el mismo sentido que el ser humano); de ello se desprende que lo que se protege es la vida o salud ${ }^{42}$ por lo que parece que ya se está reconociendo cierta independencia al animal doméstico o amansado. Ahora bien, la doctrina ha criticado que si se reconoce que el bien jurídico viene determinado por la satisfacción de necesidades humanas, el propio tenor literal del precepto une las necesidades del ser humano con los animales por cuanto al citar directamente una modalidad de animales los "domésticos", entendidos éstos, en virtud de lo conceptuado en el DRAE, como "aquel que pertenece a especies acostumbradas secularmente a la convivencia con el hombre y no es susceptible de apropiación", o que "se cría en la compañía del hombre"; en cuanto que "amansado" viene determinado por la condición de que el hombre va a cambiar la condición de salvaje del propio animal (incluyendo a los animales de renta o las mascotas exóticas) ${ }^{43}$. Así pues,

${ }^{42}$ Pese a ello, se han hecho ciertas objeciones a este planteamiento ya que se ha puesto de manifiesto que la vida y la salud del animal domestico o amansado no puede ser el objeto jurídico de protección puesto que si fuera capaz de ser sujeto pasivo también podría ser sujeto activo y ello sería imposible. La doctrina pone como ejemplo al nasciturus que no puede reclamar sus derechos, los menores, los incapaces; sin embargo, se podría realizar a través del Ministerio Fiscal, como se hace en los supuestos precitados. Otra cuestión es la de la proporcionalidad por el hecho de las penas que en el delito de lesiones o muerte se distingue en el ámbito humano y que no se diferencia en el ámbito animal; circunstancia que puede ser poco importante por cuanto puede ser un defecto de técnica legislativa por parte del legislador como en otros preceptos del texto punitivo. HAVA GARCÍA, E., "Delitos relativos a la protección de la flora, fauna y animales domésticos", en ÁLVAREZ GARCÍA, F.J., (Dir.), MANJÓNCABEZA OLMEDA, A., y VENTURA PÜSCHEL, A., (Coords.), Derecho penal español. Parte Especial (II), cit., pág. 1110. BAUCELL LLADÓS, J., "Comentarios a los delitos relativos a la ordenación del territorio y la protección del patrimonio histórico y del medio ambiente”, en CÓRDOBA RODA, J., y GARCÍA ARÁN, M., Comentarios al Código Penal. Parte Especial, Tomo I, Madrid, 2004, pág. 1468.

43 HAVA GARCÍA, E., "Delitos relativos a la protección de la flora, fauna y animales domésticos", en ÁLVAREZ GARCÍA, F.J., (Dir.), MANJÓN-CABEZA OLMEDA, A., y VENTURA., (Coords.), Derecho penal español. Parte Especial (II), cit., pág. 1114. ZAPICO BARBEITO, M., "Hacia un nuevo bien jurídico del delito de maltrato de animales domésticos y amansados", Revista Aranzadi de Derecho y Proceso penal, cit., pág. 20. 
tanto el doméstico como el amansado tienen como denominador común la relación con el ser humano, por ello creo que es el motivo suficiente para que per se esto sea la circunstancia hibrida entre los derechos de los animales y la satisfacción de intereses humanos. Por tanto, el legislador señala, seguramente con mala técnica legislativa, la independencia del bien jurídico vida e integridad física o psíquica (salud) y junto con la relación con los seres humanos que complementará fehacientemente las necesidades precisas frente al animal doméstico o amansado.

En suma, el texto actual del Código, en lo que al maltrato animal se refiere, parece indicar una mayor reivindicación por los animales en sí mismo considerados y no sólo por la sensación de piedad que generan en los seres humanos. Igualmente, nos encontramos en una traslación desde el antropocentrismo a un mayor animalcentrismo, por tanto, ante un progresivo cambio del bien jurídico basado en un moderno concepto de objeto juridico por el necesario reconocimiento de la capacidad de sufrimiento de los animales muy similar al del humano que hará reconocer al animal doméstico o amansado como algo más que meros objetos materiales del delito.

\section{Otros elementos del delito que aparecen en la sentencia}

La acción en este ilícito consiste en maltratar, realizar actos de violencia física que mediante acciones $\mathrm{o}$ incluso omisiones, sin motivo razonable $\mathrm{o}$ legítimo, causando un dolor o sufrimiento considerables o perjudiquen gravemente la salud o le causen la muerte. Se trata de un delito común de resultado material contra la salud o la vida del animal. Se incluye la acción de torturar o golpear con maldad o brutalidad, la muerte por medio de una dura 
agonía, mutilación grave, etc. La salida del concepto "enseñamiento" ${ }^{44}$ del artículo del texto punitivo ha suavizado los requisitos necesarios para la consumación del delito por lo que se trata de producir el menoscabo físico o psíquico incluso la producción de la muerte.

En la sentencia que nos ocupa, la acción típica se define por la muerte de txispa mediante dos disparos y posteriormente atravesándolo el culpable con un objeto puntiagudo con el que rompiéndole dos costillas le produjo una muerte dolorosa. Ello hace que se pueda ajustar la acción delictiva producida con lo que requiere el art. $337 \mathrm{CP}$, ya que se produce por los medios antedichos (cualquier medio o procedimiento), produciéndole de manera injustificada la muerte.

No obstante, no ha sido el único suceso de este tipo que ha sido sentenciado por cuanto otras sentencias muestras sucesos similares. Así, se pueden englobar en lo que se conoce como maltrato por diversión, por rabia u odio, sadismo o travesuras de jóvenes. De modo que estas circunstancias pueden tener lugar cuando el animal resulta molesto e incómodo (como se sabe el culpable entiende que txispas le ha matado alguna oveja de su propiedad), en venganza por relaciones de vecindad o familiares muy deterioradas 0 , a veces, sin más motivo que el de comprobar la reacción animal $^{45}$.

${ }^{44}$ AA.VV., "Los delitos relativos a la protección de la flora y fauna y los animales domésticos", en GÓMEZ RIVERO, C., (coord.), Nociones fundamentales de Derecho penal. Parte Especial (adaptado al EEES), cit., pág. 723 .

${ }^{45}$ Muchas formas de maltrato son denunciados. Como muestra puede citarse las muertes que se producen por apaleamiento o por asfixia ya sea por ahorcamiento o ahogamiento, como suele ocurrir en una práctica habitual con los galgos españoles que son abandonados o ejecutados por el mero hecho de su menor valía para ejercer el deporte de la caza con galgo y cuya duración máxima son tres años como si de los "replicantes" de la película Blade Runner se tratara, pues tiene la fecha de caducidad de cuatro años. El ahorcamiento de galgos es además práctica frecuente en algunos lugares de España, como en 2008 en Gerena (Sevilla), o en 2009 en Villatobas (Toledo) donde se encontraron más de un centenar de galgos ahorcados en un colgadero oficial porque tras un año o dos de vida y terminada la temporada de caza resultaban inservibles. Cfr. REQUEJO CONDE, C., "Maltrato de animales: Comentario a la Sentencia 135/10 del Juzgado de lo Penal no 4 de Bilbao (Bizkaia) de 25 de marzo de 2010-05-13", 
Como en el caso examinado, donde se utilizó el maltrato a base de cuchilladas o con armas u objetos punzantes, se ha condenado en algunos casos: Sentencia dictada por el Juzgado de Instrucción núm. 1 de Jaén de marzo de 2009, en la que se condenó al acusado de matar a un perro bóxer con una motosierra cuando este se peleaba con una perra propiedad del inculpado, haciéndole cortes en el cuello que provocaron heridas que acabaron con su vida. Pese a una petición mayor de pena por parte del fiscal que solicitaba tres meses de prisión, el procesado se conformó y se le impuso la pena reducida en un tercio. Otros casos similares, pueden ser, por ejemplo el de una pareja que mató a su perro bóxer de dos años que previamente había amordazado con una corbata (Madrid, 2008); un joven con las facultades mentales alteradas que ató a su husky siberiano de seis meses a un saco de boxeo y lo mató de diez puñaladas (Palma de Mallorca, 2008) ${ }^{46}$. También en la sentencia objeto de comentario se produce un abatimiento por disparos; como ejemplo de sentencias se puede citar la del agente de policía que fue imputado por maltrato por matar a tiros a su perro pitbull. Una vecina avisó a la policía tras entrar el animal en su parcela, contigua al chalet de los propietarios; el perro entró por un hueco de la alambrada que separaba ambos terrenos; también, los dueños no tenían licencia para poseer un perro de esta raza, tampoco tenían seguro de responsabilidad civil y llevaban un año sin vacunarlo (Madrid, marzo de 2006) ${ }^{47}$.

http://www.derechoanimal.info/esp/page/1462/abandono-comentario-a-la-sentencia-135or10-deljuzgado-de-lo-penal-no-4-de-bilbao-(bizkaia)-de-25-de-marzo-de-2010, pág. 6. Citado día 6 de febrero de 2013. Cfr. AA.VV., "Los delitos relativos a la protección de la flora y fauna y los animales domésticos", en GÓMEZ RIVERO, C., (coord.), Nociones fundamentales de Derecho penal. Parte Especial (adaptado al EEES), cit., pág. 723.

${ }^{46}$ Mas ejemplos pueden verse en REQUEJO CONDE, C., La protección de la fauna. Especial consideración del delito de maltrato de animales, cit., pág. 51. Estos ejemplos aparecen en la nota 84.

${ }^{47}$ Ibid., pág. 53. 
En cuanto al resultado del delito se produjo la muerte de txispas por lo que se cumple el resultado que exige el tipo penal, la muerte o lesiones ${ }^{48}$, en el caso examinado la primera.

En referencia al tipo subjetivo, se le exige el dolo directo, elemento subjetivo que también se cumple en la sentencia objeto de comentario ${ }^{49}$. Esto se puede comprobar absolutamente en la sentencia objeto de este trabajo por cuanto el inculpado posee el conocimiento y la voluntad para disparar al perro mestizo por cuanto debe advertirse la existencia del dolo directo.

Por último, comentar la consecuencia jurídica que puede ser de tres meses a un año de prisión y en el caso concreto el juez impuso la prisión de cuatro meses más la inhabilitación para profesión, oficio o comercio de uno a tres años, imponiendo el juez en la sentencia la inhabilitación especial de 1 año, sin que se haya observado ninguna circunstancia modificativa de responsabilidad criminal. Cierto es que el magistrado no ha fundamentado en exceso la sentencia, si bien es cierto que los dislates e incoherencias del legislador han hecho que la jurisprudencia no entre en mucha valoración sino que a los hechos probados se aplique el art. 337 CP sin mucha fundamentación.

En conclusión, nos encontramos con un ilícito que muestra algunas incoherencias doctrinales, si bien ahora, se esta progresando en determinar un objeto jurídico de protección donde se va delimitando uno propio basado en

${ }^{48}$ En cuanto a las lesiones, en virtud del paralelismo que existe con el delito de lesiones humanas, podría aplicarse para que se aprecie el delito delictivo que se aplique los requisitos objetivos como pueden ser la existencia de una primera asistencia facultativa y un tratamiento médico o quirúrgico. AA.VV., "Los delitos relativos a la protección de la flora y fauna y los animales domésticos", en GÓMEZ RIVERO, C., (coord.), Nociones fundamentales de Derecho penal. Parte Especial (adaptado al EEES), cit., pág. 724. En virtud de las dificultades acaecidas para realizar efectivamente la prueba de la afectación psíquica al animal en cuestión, bastará la constatación de los actos que tiene como efecto normal o lógico la producción de aquel sufrimiento psíquico.

${ }^{49}$ AA.VV., "Los delitos relativos a la protección de la flora y fauna y los animales domésticos", en GÓMEZ RIVERO, C., (coord.), Nociones fundamentales de Derecho penal. Parte Especial (adaptado al EEES), cit., pág. 724. 
los animales domésticos o amansados en virtud de su relación con el ser humano, entendiéndose que son algo más que el objeto material del delito.

\section{Bibliografía utilizada}

AA.VV., "Los delitos relativos a la protección de la flora y fauna y los animales domésticos", en GÓMEZ RIVERO, C., (coord.), Nociones fundamentales de Derecho penal. Parte Especial (adaptado al EEES), Madrid, 2010.

BAUCELL LLADÓS, J., "Comentarios a los delitos relativos a la ordenación del territorio y la protección del patrimonio histórico y del medio ambiente", en CÓRDOBA RODA, J., y GARCíA ARÁN, M., Comentarios al Código Penal. Parte Especial, Tomo I, Madrid, 2004.

BENTHAN, J., Introduccion to the Principles of morals and Legislation, London, 1970.

BLASCO, A., Ética y bienestar animal, Madrid, 2011.

CABRERA CARO, L., "Autonomía y dignidad; la titularidad de los derechos", en Anuario de los derechos humanos, vol, 3 (2002).

DE VICENTE MARTínEZ, R., Vademecum de Derecho penal, Valencia, 2011.

DE VICENTE MARTíNEZ, R., "Circunstancias de la responsabilidad criminal", en DEMETRIO CRESPO, E., (Coord.), Lecciones y materiales para el estudio del Derecho penal, Teoría del delito, Tomo II, Madrid, 2011.

DOMENECH PASCUAL, G., "La posibilidad de limitar los derechos fundamentales en aras del bienestar animal", Revista Interdisciplinar de Gestión Ambiental, 74 (2005).

GREVEN, G., Die Tierhaltung aus strafrechtlicher Sicht, 1998. 
GUZMÁN DALBORA, J.L., "El delito de maltrato de animales", en AA.VV., La ciencia del Derecho penal ante el nuevo siglo. Libro homenaje al Prof. Dr. D. José Cerezo Mir, Madrid, 2002.

HAVA GARCÍA, E., La tutela penal de los animales, Valencia, 2009.

HAVA GARCÍA, E., "Delitos relativos a la protección de la flora, fauna y animales domésticos", en ÁlVAREZ GARCíA, F.J., (Dir.), MANJÓN-CABEZA OLMEDA, A., y VENTURA., (Coords.), Derecho penal español. Parte Especial (II), Valencia, 2011. HELIZALDE HEVIA, A., "Derechos de la naturaleza. ¿Problema jurídico o problema de supervivencia colectiva?", en ACOSTA, A., y MARTínEZ, E., (comp.), Derechos de la naturaleza. El futuro es ahora, Quito, 2009.

HIGUERA GUIMERA, J.F., La protección penal de los animales en España, Madrid, 1994.

KRIELE, M., "Gesetzliche Regelungen von Tierversuchen und Wissenschaftsfreiheit", en HÄNDEL, U.M., (coord.), Tierschutz. Testfall unserer Menschlichkeit, Frankfurt a. Händel, M., 1984.

MARQUÉS I BANQUÉ, M., "Comentarios al art. 337", en QUINTERO OLIVARES, G., (dir.) y MORALES PRATS, F., (coord.), Comentarios a la parte especial de Derecho penal, 5a ed., Pamplona, 2005.

MARTínEZ-BUJÁN PÉREZ, C., Derecho penal económico y de la empresa. Parte especial, 2a ed., Valencia, 2005.

MEJÍAS, J.J., "Derechos humanos y Medio ambiente", en Humana lura, 10 (2000).

MORIE, R., Das Vergehen der Tierquälerei. Eine strafrechtliche Untersuchung zu $\S 17 T$ über bes. Berücksichtigung staatsanwalts-schaftlicher und gerichtlicher Strafakten aus Niedersachsen in den Jahren 1974-1981, 1984.

MUÑOZ CONDE, F., y GARCÍA ARÁN, M., Derecho penal. Parte general, 8 a ed., Valencia, 2010. 
MUÑOZ LORENTE, J., "Los delitos relativos a la flora, fauna, y animales domésticos: o de cómo no legislar en Derecho penal y cómo no incurrir en despropósitos jurídicos", en Revista de Derecho penal y Criminología (2007). PÉREZ MONGUIÓ, J.M., Animales de compañía, Barcelona, 2005.

RAMÓN RIBAS, E., "El maltrato de animales y la custodia de animales", en QUINTERO OLIVARES, G., (Dir.), La reforma Penal de 2010: Análisis y Comentarios, Pamplona, 2010.

REY CERVÓS, M., "Muerte de Sorky Das Point, posibles consecuencias jurídicas en el ámbito penal $y$ en el ámbito deportivo", en http://www.derechoanimal.info/esp/page/2404/muerte-de-sorky-das-pontposibles-consecuencias-juridicas-en-el-ambito-penal-y-en-el-ambito-deportivo. REQUEJO CONDE, C., La protección de la fauna. Especial consideración del delito de maltrato de animales, Granada, 2010.

RÍOS CORBACHO, J.M., "Los animales como posibles sujetos de Derecho penal. Algunas reflexiones sobre los artículos 631 (suelta de animales feroces o dañinos) y 632 (malos tratos crueles) del Código Penal español", Revista de Derecho Penal de la Universidad de Fribourg, http://perso.unifr.ch/derechopenal/assets/files/articulos/a_20080526_86.pdf, págs. 3 y ss. Citado el día 2 de febrero de 2013.

ROCA AGAPITO, L., "Algunas reflexiones sobre los animales y el Derecho penal. En particular el art. 631 del Código Penal, Actualidad Penal, 1996.

ROCA FERNÁNDEZ-CASTANYS, M.L., "Los animales domésticos y el Derecho: en particular, el régimen jurídico de los animales de compañía", en AA.VV., Panorama jurídico de las Administraciones Públicas en el siglo XXI. Homenaje al Profesor Eduardo Roca Roca, Madrid, 2002. 
RÖCKLE, A.G., Probleme und Entwicklungstendenzen des strafrechtlichen Tierschutzes, 1996.

RUÍZ RODRÍGUEZ, L.R., "Posición y tratamiento de los animales en el sistema penal", en AA.VV., Los animales como agentes y víctima de daños. Especial referencia a los animales que se encuentran bajo el dominio del hombre, Barcelona, 2008.

SERRA, J.I., "Sentencia definitiva no 86 de la Cámara de Apelaciones en lo civil y en los comercial en lo Contencioso-administrativo de Primera nominación de la segunda circunscripción judicial de Rio Cuarto (Argentina)", http://www.derechoanimal.info/esp/page/2387/los-perros-no-son-

simplemente-una-'cosa'-sentencia-definitiva-nUmero-86-de-la-camara-deapelaciones-en-lo-civil-y-comercial-y-en-lo-contencioso-administrativo-deprimera-nominacion-de-la-segunda-circunscripcion-judicial-de-rio-cuarto(Argentina).

SERRANO TÁRREGA, M. D, "El maltrato de animales en el Código Penal”, La Ley, 3 (2005).

SERRANO TÁRREGA, M.D., "El maltrato de animales", Revista de Derecho penal y Criminología, núm. Extraordinario 2 (2004).

SINGER, P., Liberación animal, Madrid, 2011.

TERRADILLOS BASOCO, J., "La satisfacción de necesidades como criterio de determinación del objeto de tutela jurídico-penal", en Revista de la Facultad de Derecho de la Universidad Complutense , 63 (1981).

VERCHER NOGUERA, A., "La reforma introducida por la Ley orgánica 15/2003, de 25 de noviembre en materia penal ambiental o la exigencia de un reajuste inevitable", en Actualidad Jurídica Aranzadi, 665 (2005).

ZAPICO BARBEITO, M., "Hacia un nuevo bien jurídico del delito de maltrato de animales domésticos y amansados", Revista Aranzadi de Derecho y Proceso penal, no 25 (2011). 